\title{
Health Literacy and Health Outcomes of Adults in the United States: Implications for Providers
}

\author{
Marilyn McDonald \\ Purdue University Global, marilyn.mcdonald@purdueglobal.edu \\ Laura J. Shenkman \\ Purdue University Global School of Nursing, Ishenkman@purdueglobal.edu
}

Follow this and additional works at: https://nsuworks.nova.edu/ijahsp

Part of the Medicine and Health Sciences Commons

\section{Recommended Citation \\ McDonald M, Shenkman LJ. Health Literacy and Health Outcomes of Adults in the United States: \\ Implications for Providers. The Internet Journal of Allied Health Sciences and Practice. 2018 Jan 01;16(4), Article 2.}

This Manuscript is brought to you for free and open access by the College of Health Care Sciences at NSUWorks. It has been accepted for inclusion in Internet Journal of Allied Health Sciences and Practice by an authorized editor of NSUWorks. For more information, please contact nsuworks@nova.edu. 


\title{
Health Literacy and Health Outcomes of Adults in the United States: Implications for Providers
}

\begin{abstract}
The purpose of this paper is to explore health literacy of adults in the United States and review health outcomes as well as provider implications. Limited health literacy is a serious problem in the United States. Approximately 80 million adults in the United States have limited health literacy, which can adversely affect the quality of their health care. Poor health outcomes are associated with being health illiterate. Evidence shows that limited health literacy is associated with more hospitalizations; greater use of emergency care; lower receipt of mammography screening and influenza vaccine; poorer ability to demonstrate taking medications properly; poorer ability to interpret drug labels and health messages; and, among elderly persons, poorer overall health status and higher mortality rates. Health literacy is essential for patients to be able to take control and manage their own health. The benefits of being health literate include greater patient safety, less hospitalizations, a greater ability to care for oneself, and a greater cost savings to the healthcare system. This paper emphasizes "best practices" recommended by the World Health Organization (WHO) ${ }^{1}$ The American Medical Association (AMA), ${ }^{2}$ the Institute of Medicine (IOM), ${ }^{3}$ the Center for Disease Control (CDC), ${ }^{4}$ and the Joint Commission (JCAHO) ${ }^{5}$ When patients, providers and communities work together to understand and improve health literacy a greater quality of life will result. Today's health care providers are in a position to make an impact on the health illiteracy epidemic and improve the patient's understanding about their health and outcomes.
\end{abstract}

\section{Author Bio(s)}

Dr. Marilyn McDonald DHSc, APRN, AGNP is the Adult-Gero Nurse Practitioner Program Lead in the Nurse Practitioner program at Purdue University Global. She received her MSN at Yale University and her DHSc at Nova Southeastern University. She practices as an AGNP at The Rutland Free Clinic in Rutland, Vermont.

Professor Laura Shenkman FNP-C, APRN, MSN is the Family Nurse Practitioner Program Lead in the Nurse Practitioner program at Purdue University Global. She received her MSN from Duke University. She is currently a doctoral candidate in nursing at Purdue University Global. She practices as an FNP in rural North Carolina. 


\title{
IJAHSP \\ The Internet Joưnal of Allied Health Sciences and Practice
}

Dedicated to allied health professional practice and education

Vol. 16 No. 4 ISSN 1540-580X

\section{Health Literacy and Health Outcomes of Adults in the United States: Implications for Providers}

\author{
Marilyn McDonald, DHSc, APRN, AGNP \\ Laura J. Shenkman, FNP-C, APRN, MSN \\ Purdue University Global \\ United States
}

\begin{abstract}
The purpose of this paper is to explore health literacy of adults in the United States and review health outcomes as well as provider implications. Limited health literacy is a serious problem in the United States. Approximately 80 million adults in the United States have limited health literacy, which can adversely affect the quality of their health care. Poor health outcomes are associated with being health illiterate. Evidence shows that limited health literacy is associated with more hospitalizations, greater use of emergency care, lower receipt of mammography screening and influenza vaccine, poorer ability to demonstrate taking medications properly, poorer ability to interpret drug labels and health messages, and, among elderly persons, poorer overall health status and higher mortality rates. Health literacy is essential for patients to be able to take control and manage their own health. The benefits of being health literate include greater patient safety, less hospitalizations, a greater ability to care for oneself, and a greater cost savings to the healthcare system. This paper emphasizes "best practices" recommended by the World Health Organization (WHO), The American Medical Association (AMA), the Institute of Medicine (IOM), the Center for Disease Control (CDC), and the Joint Commission on the Accreditation of Healthcare Organizations (JCAHO). ${ }^{1-5}$ When patients, providers, and communities work together to understand and improve health literacy, a greater quality of life will result. Today's health care providers are positioned to make an impact on the health illiteracy epidemic and improve the patient's understanding about their health and outcomes.
\end{abstract}

\section{Health Literacy and Adults in the United States}

Approximately 80 million or greater than thirty percent of adults in the United States are thought to have limited "health literacy." 6 Awareness of health literacy has been evolving for several decades. Numerous definitions of health literacy exist. Pleasant et al. found that the most cited definition to date originated in $2000 .{ }^{7}$ In 2000, Ratzan and Parker defined health literacy as "the capacity of individuals to obtain, process, and understand basic health information and services needed to make appropriate health decisions." 8 The U.S. Department of Health and Human Services then began to use this definition in Healthy People 2010. In 2004, the IOM used this definition in the widely cited report, Health Literacy: A Prescription to End Confusion. ${ }^{3}$ In 2013, the WHO provided an even broader definition: "Health literacy entails people's knowledge, motivation, and competences to access, understand, appraise, and apply health information in order to make judgements and decisions in everyday life concerning healthcare, disease prevention, and health promotion to maintain or improve quality of life during the health course."1

Health literacy is important because when a person is health illiterate, it is difficult for them to read prescriptions, medication labels, patient education material, medical forms, appointment slips, and discharge instructions. Being health literate also applies to the use of electronic technology which is being increasingly used to convey health information. There are different degrees of health literacy. In general, the literature refers to low or limited health literacy and high or strong health literacy. Even people with strong literacy skills may have trouble obtaining, understanding, and using complex health information. The WHO defines a person with strong health literacy skills as someone who has the abilities or tools needed to understand and participate in their health care decisions. ${ }^{1}$ Thus, health literacy is essential to taking control of and managing one's health. It means more than being able to read pamphlets and successfully make appointments. Furthermore, health literacy is important because it affects one's overall health

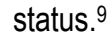




\section{Health Literacy and Patient Outcomes}

A search was conducted using PubMed, Cumulative Index of Nursing and Allied Health Literature (CINAHL), Education Resources Information Center (ERIC), and Cochrane Library to find systematic reviews that examined health literacy, patient outcomes, and implications for providers. Numerous studies were found that explored a wide range of patient populations and health literacy. However, there was much variability in the study populations and interventions to improve health literacy, and illnesses and methodologies were varied. A significant gap in the recent literature was found when searching for systematic reviews of health literacy and adults, health outcomes, and implications for providers. The most recent and the most relevant systematic review in 2011 conducted by Berkman et al concluded that individuals with limited health literacy are at greater risk for poorer health outcomes and have less access to healthcare. ${ }^{9}$ Berkman et al found that "low health literacy was consistently associated with more hospitalizations, greater use of emergency care, lower receipt of mammography screening and influenza vaccine, poorer ability to demonstrate taking medications appropriately, poorer ability to interpret labels and health messages, and among elderly persons,

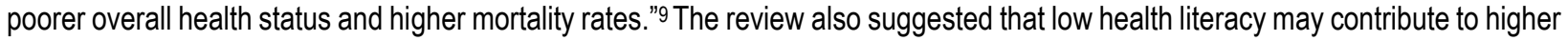
health service costs. ${ }^{9}$ Therefore, health literacy may affect the health of Americans and the ability of the health care system to provide effective, high quality health care. Thus, healthcare providers need to have a keen understanding of what it means for patients to be health illiterate as patient safety may be compromised.

Although the most relevant systematic review was conducted in 2011, another more focused systematic review of health literacy and patient outcomes in chronic kidney disease published in 2017 suggests that limited health literacy is associated with adverse clinical events, increased healthcare use, and mortality. ${ }^{10}$ Two other articles explored the relationship of health literacy and patient outcomes in patients with heart failure. In 2016, Wu et al explored health literacy, age, and health outcomes in outpatients with heart failure. ${ }^{11}$ The study examined 575 rural patients with heart failure, and the researchers found that older patients with heart failure were more likely to have low health literacy. Health outcomes were significantly worse in patients greater than age 65 . Specifically, the researchers found that the heart failure patients with low health literacy had greater rates of readmission and greater cardiac mortality over a two year period. ${ }^{11}$ In a similar study by Moser et al., the association of health literacy as a predictor of morbidity and mortality in rural patients with heart failure was examined..$^{12} \ln 575$ rural patients hospitalized with heart failure, the researchers found that low health literacy was a factor in hospital readmissions. ${ }^{12}$ Thus, low health literacy is a risk factor for poor health outcomes as well as hospital readmissions in patients with heart failure. More research is needed to look at the relationship of low health literacy and health outcomes in other illnesses.

\section{National Data}

No recent national data exists that measures health literacy. However, limited health literacy is an important public health issue. The National Assessment of Literacy (NAAL) was conducted in 2003 and the results were published by Kutner et al in 2006. ${ }^{13}$ Although the survey was conducted in 2003 , it is the only population data to date that examined literacy and health literacy in the United States. The study was conducted by the U.S. Department of Education, and more than 19,000 adults responded to the survey. The study measured 4 levels of health literacy. The 4 levels used for measurement were identified as follows: Below Basic, Basic, Intermediate, and Proficient. ${ }^{13}$ According to the NAAL, only 12 percent of adults have proficient health literacy. The survey found that 36 percent of adults have limited health literacy. The survey indicated that Hispanics, Blacks, American Indians, and Alaskan Natives are more health illiterate than Caucasians. Additional factors contributing to low health literacy included low education, poverty, age, recent refugees and immigrants, and those that did not speak English before starting school. ${ }^{13}$

The NAAL found that older adults were the highest risk group for limited health literacy. Fifty nine percent of adults over age 65 who responded to the NAAL reported limited health literacy. ${ }^{13}$ Older adults may already be compromised with sensory and/or cognitive deficits putting them at greater risk. Many older adults are more likely to have a chronic illness. Additionally, many older adults may lack social support The implications for an older adult with physical, social, and cognitive deficits could limit their understanding regarding their medical regime. Thus, older adults are at risk for several factors that may affect their safety. More research is needed to explore this relationship in the vulnerable older adult population. ${ }^{14}$

Additionally, many older adults lack access or are unable to use electronic technology..$^{14}$ Older adults may have more difficulty than a younger adult when using electronic technology. Health literacy related to electronic technology is a significant part of the health illiteracy issue because much of healthcare information is now delivered in an electronic format. A 2016 systematic review examining electronic health literacy in underserved populations concluded that advanced age was consistently associated with lower levels of electronic health literacy. ${ }^{14}$

(c) The Internet Journal of Allied Health Sciences and Practice, 2018 


\section{Measurement}

Health care providers are on the frontline and can have an impact on the literacy epidemic by providing early intervention to promote better communication of health information. Although there are a number of tools that screen for health literacy (Table 1), they are generally reserved for research. ${ }^{6}$ Screening tools vary in their approach and in the time required to utilize them by a provider. Evidence suggests that routine screening for health literacy has not shown an improvement in health outcomes and is not recommended. ${ }^{6}$ Moreover, there has been a lack of progress in identifying effective measure of health literacy. The lack of progress in identifying effective health literacy measures may be due to the broad definitions of health literacy that currently exist. Future research needs to explore whether current health literacy tools are adequate or more comprehensive assessments are better able to identify health literacy problems both for clinical and research purposes. Until more research is available, it is recommended that health care providers use understandable language and provide educational materials to all patients regardless of their literacy or educational level. ${ }^{3}$ Providers need to look for other cues that a patient may be health illiterate, such as poor compliance with treatment and appointments, difficulty filling out forms, and confusion about medications.

\section{Role of the Provider and Interventions}

Part of the problem contributing to low health literacy may be the patient care provider. Literature from the past two decades widely acknowledges poor physician-patient communication as a major health-care challenge. ${ }^{6}$ However, there is a significant gap in the more recent literature on health care provider communication and patients with low health literacy. The recent research is sparse on how culture, language, and communication between a patient and provider affects a patient's understanding of their medical regime. A report by JCAHO titled "What Did the Doctor Say" states that health literacy may be unrecognized and misunderstood by providers. If the provider does not understand the patient or the context within which the patient receives information, an adverse event affecting patient safety may occur. The number of health illiterate adults is enormous; therefore, all patients should be considered at risk. Health care providers are in a unique position to assist patients with low literacy skills.

Many patients are confused with certain medical terms, have trouble understanding English, and cannot read or write. ${ }^{15}$ Many have limited access to health care providers. It is important for health care professionals to develop a comprehensive response to the health literacy challenges and help patients and families better understand their health. The AMA and The Agency for Healthcare Quality and Research (AHQR) endorse the use of universal precautions to minimize the risk that a patient will not understand the health information they are given.,216 Universal precautions mean that all patients should be considered at risk for limited health literacy. By using this approach, no patient is overlooked.

Currently, a number of health literacy "best practices" have been recommended by the WHO, the AMA, the Institute of Medicine, the $\mathrm{CDC}$, and JCAHO to help providers better communicate with patients and families. ${ }^{1-5,13}$ Evidence-based recommendations have been developed to improve consumer information, promote comprehension, and increase adherence to recommended health actions as part of a larger patient safety and positive patient outcomes initiative. $2,5,17 \mathrm{An}$ example of this was improving prescription drug labeling. However, there are only a few systematic reviews to date that examine the relationship of interventions to improve health literacy. ${ }^{18}$

Evidence shows that the "teach-back method" has demonstrated improved health literacy, patient recall, increased comprehension, and increased disease specific outcomes. ${ }^{18}$ The "teach-back method" also called the "show-me method" is an evidence-based best practice communication tool that should be used by all health care providers. "Teach-back" was designed to explain the selfmanagement process by assessing the patient's knowledge and then asking them to teach it back to the provider. $15,18,19,20$ The provider can then clarify if the patient is able to understand all that was explained. When confirming a patient's understanding, it is best to avoid questions such as, "Do you understand?" or "Do you have any questions?" That strategy usually leads to an agreeable response that may not be accurate. Rather, it is suggested to say, "Tell me what you've understood about this medicine?" or "I want to make sure I have explained your medicine clearly. Can you tell me how you think you will take this medicine?" If the patient understands, they should be able to "teach-back" the information accurately. This cycle can be repeated until there is a shared understanding. The format is to teach, assess, clarify, and understand. Repeating the process actively involves the patient in their own care. When designing messages for patients, clinicians should focus on the need to know and need to do while avoiding extraneous information. For example, pathophysiology rarely helps the patient. A clinician should reinforce what the patient already knows and then teach what they do not know.

Patient communication should be purposeful and patient-centered. Checking patient understanding is so important that Healthy People 2020 includes it as a national public health objective. 12,19 The likelihood that patients will gain knowledge and understanding of their health lies in the provider's ability to present information in an accurate and simple manner. Patient education materials

(c) The Internet Journal of Allied Health Sciences and Practice, 2018 
can always be improved to be user friendly and age appropriate. The following "best practices" and communication techniques recommended by national organizations (Table 1) should be used by providers:

- Make effective communication an organizational priority to protect the safety of patients

- Use the "teach back" method

- Speak clearly and use plain language, avoiding medical jargon and technical terms

- Use universal precautions and consider every patient at risk for limited health literacy

- Look for "red flags" when a patient cannot correctly fill out forms or is noncompliant with the medical regime

- Include a question on the patient's ability to understand written material when taking a social history

- Create a patient centered environment from the reception desk to the patient's discharge

- Listen carefully to the patient

- Speak slowly and clearly

- Limit information to 3 key points

- Be specific and concrete. If action is involved, go through every detail

- $\quad$ Allow time for patient understanding and questions

- Reinforce the spoken word with other teaching modules such as handouts which should be written at a sixth grade reading level

- $\quad$ Develop teaching tools for non-English speaking patients

- Know when to involve an interpreter to help translate in another language if necessary

- Videos, pictures and graphs can help to enhance the patients understanding

- The older adult may need large print

- The caregiver of an older adult should always be included

- Older adults may need referral to their community aging and disability resource center for additional assistance

- Repeat and summarize the information

- Verify the patients understanding by allowing time for questions, teach-back and clarification

- A follow up with the patient is essential to ensure that the patient understands the plan of care

Table 1. Resources for Providers

\begin{tabular}{|rl|}
\hline 1. & $\begin{array}{l}\text { Agency for Healthcare Research and Quality. Universal Precautions Toolkit } \\
\text { http://www.ahrq.gov/professionals/quality-patient-safety/quality-resources/tools/literacy-toolkit/ }\end{array}$ \\
\hline 2. & Center for Disease Control http://www.cdc.gov/healthliteracy \\
\hline 3. & $\begin{array}{l}\text { Health Literacy: A Prescription to End Confusion. This Institute of Medicine report } \\
\text { recommends actions to promote a health-literate society. } \\
\text { https://www.nap.edu/catalog/10883/health-literacy-a-prescription-to-end-confusion }\end{array}$ \\
\hline 4. & $\begin{array}{l}\text { Plain Language Thesaurus for Health Communications } \\
\text { http://www.plainlanguage.gov/populartopics/health_literacy/ }\end{array}$ \\
\hline 5. & $\begin{array}{l}\text { The Joint Commission. Attributes of a Health Literate Organization. } \\
\text { www.jointcommission.org/assets/1/6/10attributes.pdf }\end{array}$ \\
\hline 6. & $\begin{array}{l}\text { World Health Organization. Health literacy: The solid facts. } \\
\text { 2013.http://www.euro.who.int/data/assets/pdf_file/0008/190655/e96854.pdf }\end{array}$ \\
\hline
\end{tabular}

\section{Conclusion}

Limited health literacy is a serious problem in the United States. Poor patient outcomes are associated with being health illiterate. The benefits of being health literate include greater patient safety, less hospitalizations, a greater ability to care for oneself, and a better overall health status. More research and systematic reviews are needed to examine health literacy in adults and associated outcomes along with implications for providers. Future research is needed to explore the efficacy of screening a patient for health literacy levels. Future research also needs to examine if specific interventions to improve health literacy lead to the use of different 
interventions to improve outcomes for specific populations. Resources are available to assist both patients and providers. When patients, providers, and communities work together to understand and improve health literacy, a greater quality of life will result.

\section{REFERENCES}

1. World Health Organization. Health Literacy: The Solid Facts. 2013. Available at: http://www.euro.who.int/data/assets/pdf_file/0008/190655/e96854.pdf. Accessed May 14, 2018.

2. Weiss BD. Health Literacy and Patient Safety: Help Patients Understand. Manual for Clinicians, 2e. Chicago, IL: American Medical Association Foundation and American Medical Association; 2007.

3. Institute of Medicine. Health Literacy: A Prescription to End Confusion. Washington, D.C.: National Academies Press: 2004.

4. Center for Disease Control and Prevention. Health Literacy. Available at: https://www.cdc.gov/healthliteracy/index.html. Accessed May 14, 2018.

5. The Joint Commission. What did the Doctor Say? Improving health literacy to protect patient safety. Oakbrook Terrace, IL: The Joint Commission; 2007. Available at: https://www.jointcommission.org/what_did_the_doctor_say._Accessed May 14, 2018.

6. Hersh L, Salzman B, Snyderman D. Health literacy in primary care practice. Am Fam Physician. 2015;92(2):118-24. [PMID: 26176370]

7. Pleasant A, Rudd RE, O'Leary C, Paasche-Orlow MK, Allen MP, et al. Considerations for a new definition of health literacy. Discussion paper. National Academy of Medicine, Washington, DC. Available at: www.nam.edu/wpcontent/uploads/2016/04/Considerations-for-a-New_Definition-of-Health-Literacy.pdf. Accessed May 14, 2018.

8. Ratzan SC, Parker SM. Introduction. In National Library of Medicine Current Biographies in Medicine: Health Literacy, 2000. NLM Pub. No. CBM 2000-1, editors Selden CR, Zorn M, Ratzan SC, Parker RM. Bethesda, MD: National Institutes of Health, U.S. Department of Health and Human Services, 2000.

9. Berkman ND, Sheridan SL, Donahue KE, Hapern DJ, Crotty K. Low health literacy and health outcomes: An updated systematic review. Ann Intern Med. 2011;155(2):97-101. [PMID: 21768583)

10. Taylor DM, Fraser S, Dudley C, Oniscu GC, Tomson C, et al. Health literacy and patient outcomes in chronic kidney disease: a systematic review. Nephrol Dial Transplant: 2017. [PMID: 29165627)

11. Wu JR, Moser DK, DeWalt DA, Rayens MK, Dracup K. Health literacy mediates the relationship between age and health outcomes in patients with heart failure. Circ Heart Fail. 2016;9(1):e002250. [PMID: 26721913]

12. Moser DK, Robinson S, Biddle MJ, Pelter MM, Nesbitt TS, et al. Health literacy predicts morbidity and mortality in rural patients with heart failure. J Card Fail. 2015;21(8):612-8. [PMID: 25908018)

13. Kutner M, Greenberg E, Jin Y, Paulsen C. The Health Literacy of America's Adults: Results from the 2003 National Assessment of Adult Literacy. (NCES 2006-483). US Department of Education. Washington, DC: National Center for Education Statistics, 2006.

14. Chesser A, Burke, A, Reyes J, Rohrberg T. Navigating the digital divide: A systematic review of ehealth literacy in underserved populations in the United States. Inform Health Soc Care. 2016;41(1):1-19. [PMID: 25710808)

15. White M, Garbez R, Carroll M, Brinker E, Howie-Esquivel J. Is 'teach-back' associated with knowledge retention and hospital readmission in hospitalized heart failure patients. J Cardiovasc Nurs. 2013;28(2):137-46.[PMID: 22580624]

16. Agency for Healthcare Research and Quality. Universal Precautions Toolkit. Available at: http://www.ahrq.gov/professionals/quality-patient-safety/quality-resources/tools/literacy-toolkit/. Accessed May 14, 2018.

17. The Joint Commission. Attributes of a Health Literate Organization. Available at: http://www.jointcommission.org/assets/1/6/10attributes.pdf. Accessed May 14, 2018.

18. Stormacq C, Wosinski J, Van den Broucke S. The effectiveness of health literacy interventions on health-related outcomes among socioeconomically disadvantaged adults living in the community: a systematic review protocol. JBI Database System Rev Implement Rep.2016 Feb;14(2):49-63. [PMID: 27536793)

19. Koo LW, Horowitz AM, Radice SD, Wang MQ, Kleinman DV. Nurse Practitioners' use of communication techniques: results of a Maryland oral health literacy survey. PLoS One. 2016 Jan;11(1):e0146545. [PMID: 26766557)

20. Negarandeh R, Mahmoodi H, Noktehdan H, Heshmat R, Shakibazadeh E. Teach back and pictorial image educational strategies on knowledge about diabetes and medication/dietary adherence among low health literate patients with type 2 diabetes. Prim Care Diabetes. 2013:7(2):111-8. [PMID: 23195913) 